\title{
IGNITION DELAY OF REACTIVITY CONTROLLED COMPRESSION IGNITION (RCCI) FOR THE MIXTURE OF DiESEl FUEL AND ETHANOL IN A RAPID COMPRESSION MACHINE
}

\author{
Juan C. V. Loaiza ${ }^{1}$, Fernando Z. Sánchez ${ }^{1}$, Oberdan M. R. De Souza ${ }^{1}$ e Sergio L. Braga ${ }^{1}$ \\ ${ }^{1}$ Pontifical Catholic University of Rio de Janeiro \\ E-mails: jc_valdez@esp.puc-rio.br, zegarra@puc-rio.br, oberdanmiguel@,gmail.com e \\ slbraga@,puc-rio.br
}

\begin{abstract}
The power generation, used to promote comfort, mobility and others continually grows. To solve this growing demand, efforts have been directed towards the development of new energy sources, preferably renewable, and better ways of energy conversion by increasing the processes efficiencies. A good example of this is the gradual shift from conventional and highly inefficient vehicles, being replaced by hybrids or purely electrics. But even with gradual migration for more efficient energy use, we will continue depending of traditional fuels therefore it is necessary to develop more efficient and less polluting ways to use these sources. Thus, this work aims to study alternative ways of converting energy contained in fuels used in internal combustion engines by use of combustion mode RCCI, two fluids with different cetane numbers are introduced into the combustion chamber at different times with the purpose of burning the fuel with lower cetane number. Therefore, for combustion mode RCCI, the SOI of fuel with lower enthalpy of vaporization and the start of combustion must be determined to determine the ignition delay. The results show the ignition delays for the different techniques of injection of fuels with compression ratios of 16:1 and 20:1.
\end{abstract}

\section{INTRODUCTION}

The environmental area began to be discussed in the international relations from the 1960s, specifically in 1968 with the Club of Rome, later in 1972, with the realization of the United Nations Conference on the Human Environment in Stockholm [1]. Due to the use of oil on a large scale in the last 70 years, projections show the depletion of international reserves which contributed to the high increase of the price [2]. The severe rise in crude oil prices since 1973 has placed increasingly sensitive loads on the trade balances of the non-oil-producing countries and has come to represent threat to the developing countries existence [3]. The fear that mineral oil energy in the future will be not available has increased the interest in the possibility of finding substitutes for petroleum products. One country which has the ideal climatic and geographical conditions for the substitution of mineral oil by biomass-based fuels is Brazil. With the knowledge of these possibilities, the Brazilian Government issued a decree in 1975 establishing the "National Alcohol Plan", which provide for a great increase in 
ethanol production. This nation-wide program financed by the government had as objective to phase out automobile fuels derived from fossil fuels, such as gasoline, in favor of ethanol produced from sugar cane [4].

Bioethanol is the best alternative fuel for the Otto engines while biodiesel is used for diesel engines. Nowadays, some studies have considered the utilization of alcohol in a diesel vehicle. The use of this fuel in a compression ignition (CI) engine is a challenge due to the lower cetane number, lubricity and viscosity, among other factors [5]. Attempts for using alcohol fuel in a compression ignition engine typically involve major modifications to the basic diesel engine such as the increase in the volume of fuel injected by changing the injection timing and the fuel injection pressure. Others modifications include the increase of the vehicle fuel tank and the addition of fuel additives for lubricity and ignition improvement [6]. The main environmental problem for the use of alcohol fuel in diesel engines is an increased level of unburned or partially burned fuel. The first attempts to use alcohol (ethanol or methanol) as a CI engine fuel did not lead to ignition. One of the most serious problems to be overcome is alcohol's poor ignitability under diesel engine conditions [7]. This is generally attributed to the high enthalpy of vaporization of alcohols and a higher auto ignition temperature when compared to diesel.

Another methodology for the use of ethanol in compression ignition engines is the dual fuel mode [8], where ethanol and diesel oil are mixed into the combustion chamber. The objective is replace the higher amount of Diesel oil by ethanol and this way, a small amount of Diesel oil will start the combustion.

\section{REACTIVITY CONTROLLED COMPRESSION IGNITION (RCCI) COMBUSTION}

RCCI is a dual fuel engine combustion technology that was developed at the University of Wisconsin-Madison Engine Research Center laboratories. RCCI is a modification of Homogeneous Charge Compression Ignition (HCCI) that provides more control over the combustion process and has the potential to lower fuel use and the emissions [9]. This is the combustion mode that closely resembles the conditions that are attempted to be achieved during the experiments conducted in this study. RCCI uses incylinder fuel blending with at least two fuels of different reactivity (different auto-ignition power or different cetane number) and multiple injections to control in-cylinder fuel reactivity to optimize combustion phasing, duration and magnitude. The process involves introduction of a low reactivity fuel into the cylinder to create a well-mixed charge of low reactivity fuel, air and recirculated exhaust gases. The high reactivity fuel is injected before the ignition of the premixed fuel occurs, using single or multiple injections directly into the combustion chamber. Examples of fuel pairings for RCCI are gasoline and diesel mixtures, ethanol and diesel and gasoline with small additions of a cetane-number booster (di -tert-butyl peroxide (DTBP) [10].

RCCI allows optimization of HCCI and Premixed Controlled Compression Ignition (PCCI) type combustion in diesel engines, reducing emissions and the need for after-treatment methods. The Fig. 1 shows the development of new injection strategies with simultaneous use of two fuels with different auto-ignition power. 


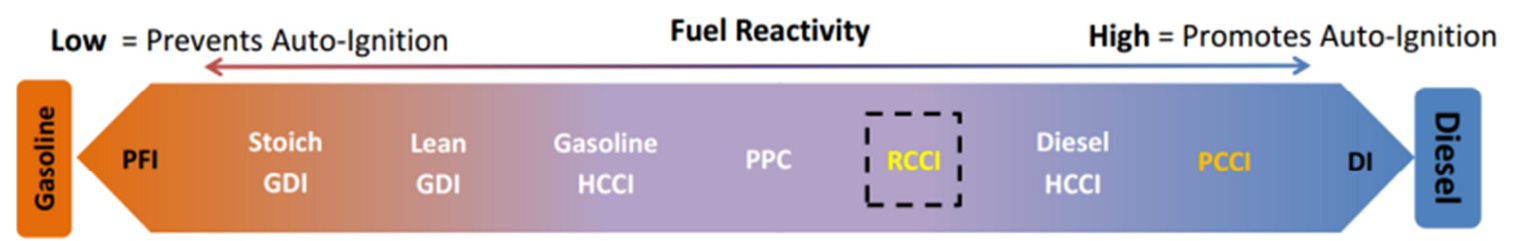

Figure 1. Advanced combustion strategies converging on hardware and fuel [11].

By appropriately choosing the reactivities of the fuel charges, their relative amounts, timing and combustion can be tailored to achieve optimal power output (fuel efficiency) at controlled temperatures (controlling NOx) with controlled equivalence ratios (controlling soot). Key benefits of the RCCI strategy include [12]:

- Lower PM and NOx emissions

- Reduced heat transfer losses

- Increased combustion efficiency

\section{ANALYSIS OF IGNITION DELAY}

Ignition Delay or Delay Time is the time between the beginning of fuel injection into the combustion chamber and the beginning of combustion [13]. Therefore, the start of pilot diesel injection and the start of combustion must be known to determine the ignition delay of dual fuel operated engine [14]. The start of pilot diesel injection can be defined as the time when the injector needle is lifted off its seat by the needle-lift indicator. However, it is very difficult to define the start of pilot diesel combustion. Many defining methods were suggested to obtain the start of combustion for diesel engines. The methods to determine the ignition delay can be broadly classified into two categories: The direct (DM) and the indirect (IM) methods [15]. This period in the diesel engine exerts a great influence on both engine design and performance.

Functionally, the ID can be divided into two parts: the physical and chemical delay. The physical delay is the time between the beginning of injection and the attainment of chemical reaction conditions. During this period, the fuel is atomized, vaporized, mixed with air and brought to self-ignition temperature. Viscosity governs the physical delay of fuel combustion process. For low viscosity fuels, the physical delay tends to be small and vice versa. During the chemical delay, the reactions start slowly and then accelerate until inflammation or ignition conditions are reached. Generally, chemical delay is longer than the physical delay. However, it depends on the temperatures of the surroundings. Chemical reactions are faster at higher temperatures thus physical delay becomes longer than the chemical delay [16].

The direct method is based on the measurement of flame position versus time. This method consists in a huge modification of the combustion chamber once it's necessary to install a quartz window in order to visualize the flame. Besides the quartz window, a high speed camera is needed to capture the phenomenon of combustion. Another direct method is by means of flame ionization detector and the associated electronics. The indirect method is based on the pressure - time history of a working cycle. With a pressure sensor installed in the cylinder head is possible to capture accurately the variation of pressure with respect to time. However, $\mathrm{P}$ - T curves are not able to provide directly the combustion parameters. Some amount of personal judgment is required for the evaluation of ignition delay and combustion duration. This difficulty has made the method a little less accurate. Some researchers have 
suggested methods for evaluating the delay time by heat release from pressure-time data. Another suggestion is to use the $\log \mathrm{P}-\log \mathrm{v}$ curve, which would enable the determination of an average value of the polytropic coefficient, $\mathrm{k}$. The straight line portion of the compression process will start deviating from its path with the start of combustion. The first and second derivatives of pressure curve with respect to time ( $d p$ and $d^{2} p$ ) also allows the evaluation of the ID within a good accuracy [15], these methods were used in this study to determine the ignition delay for the tests made.

\section{EXPERIMENTAL SETUP}

The experimental setup used for this study is shown in Fig. 2. The Rapid Compression Machine (RCM) is installed at the Vehicular Engineering Laboratory (VEL) at PUC-Rio. This machine is able to quickly and easily operate at Otto and Diesel cycles.

RCM simulates a single compression and a partial expansion process, which allows more detailed studies of injection, mixing, vaporization, ignition, flame development and combustion. This includes optical diagnostics, piston displacement and combustion chamber pressure data collection. Table 1 summarizes RCM main specifications. The operation of RCM can be explained by three different systems with predetermined functions: pneumatic, hydraulic and fuel injection.

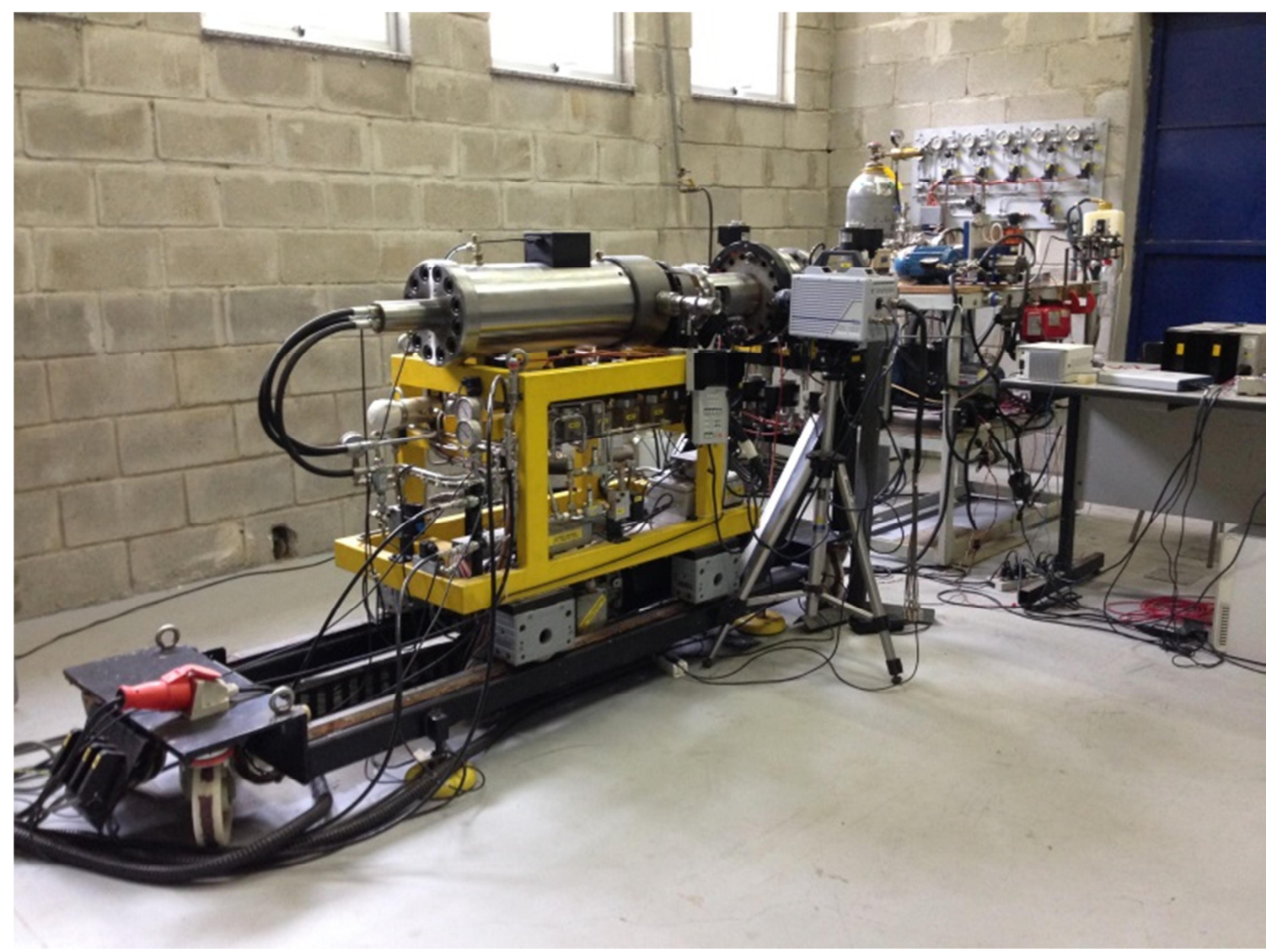

Figure 2. RCM installed on VEL at PUC - Rio. 
These systems work basically for RCM drive train and test section. Pneumatic system provides pressure to drive the RCM and air for the combustion process. It is basically composed by a cylinder for compressed air storage, compressor, piston, pressure sensors, lines and valves. Hydraulic system works on main RCM functions, generating the test shot that will perform the compression and partial expansion strokes. Furthermore, this system ensures the seal between the drive train and test section, keeping those parts coupled. It basically contains an oil reservoir, oil piston and pump, lines, valves and pressure sensors.

Table 1. Important specifications of the RCM.

\begin{tabular}{|l|l|}
\hline Piston diameter $(\mathrm{mm})$ & 84 \\
\hline Piston stroke (mm) & $120-249$ \\
\hline Compression ratio (-) & $5-25$ \\
\hline Simulation of rotations (rpm) & $1500-3500$ \\
\hline Direct injection System & Diesel and Otto \\
\hline Max. shot performance & 30 single shots/h \\
\hline Max. combustion pressure (bar) & 200 \\
\hline Driving pressure (bar) & $0-50$ \\
\hline Cylinder / piston head max. temperature $\left({ }^{\circ} \mathrm{C}\right)$ & 120 \\
\hline
\end{tabular}

For the tests of dual fuel injection, a pressure sensor and two injectors were installed in the RCM head as shown in Fig. 3 and 4. Fig. 3 shows the piston position near the TDC and in the $\mathrm{BDC}$ respectively. Can observe the position of the injectors, the diesel injector is installed in the center of the head, the ethanol injector is installed the $17 \mathrm{~mm}$ to the right of diesel injector with a tilt angle of 7 degrees to the vertical and the pressure sensor is installed the $20 \mathrm{~mm}$ to the left of diesel injector.

The injection system of diesel is made by using a common rail system that provides maximum injection pressure of 1800 bar. The injection system of ethanol is done by using an injector of Spark-ignition engine (engine EP 6), that supports injection pressures of up to 100 bar. The feed system for the common rail of ethanol was done by pressurizing the ethanol in a reservoir of 1.51 . 

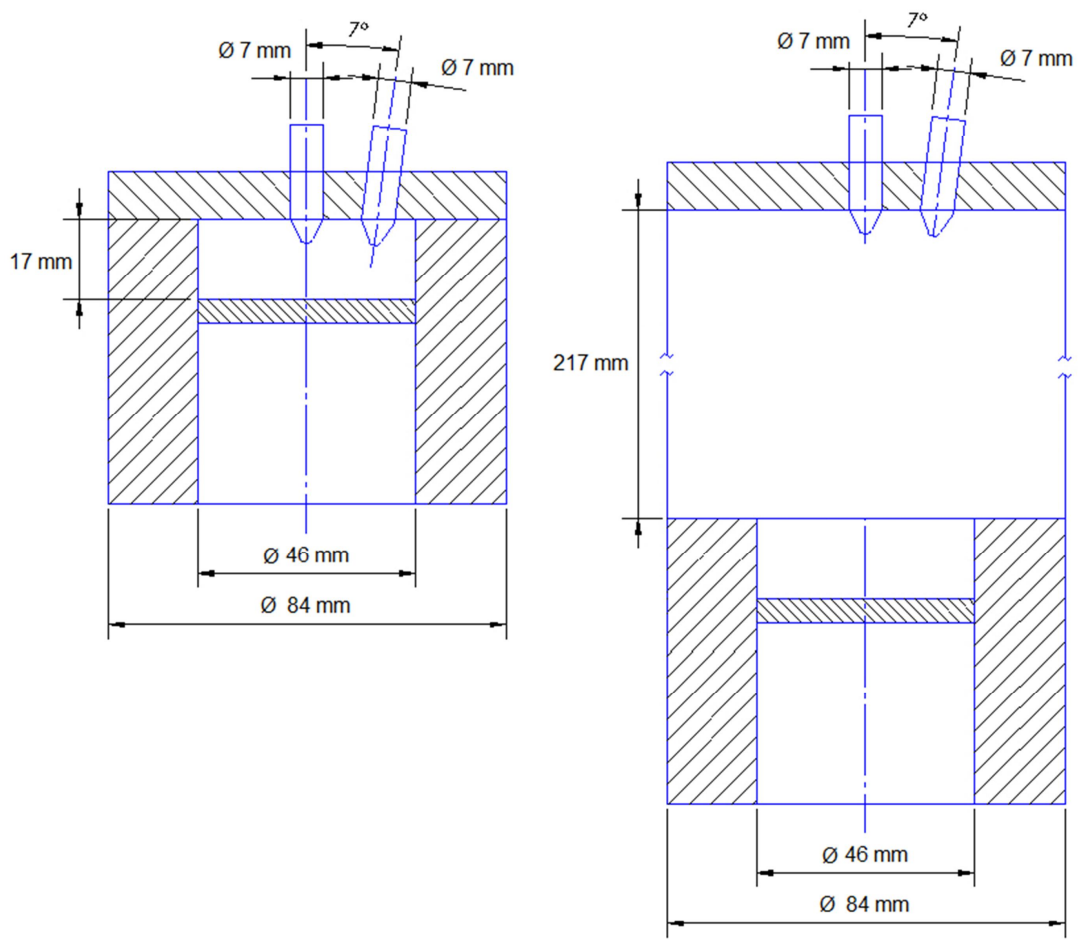

Figure 3. Geometric data of dual fuel configuration in RCM

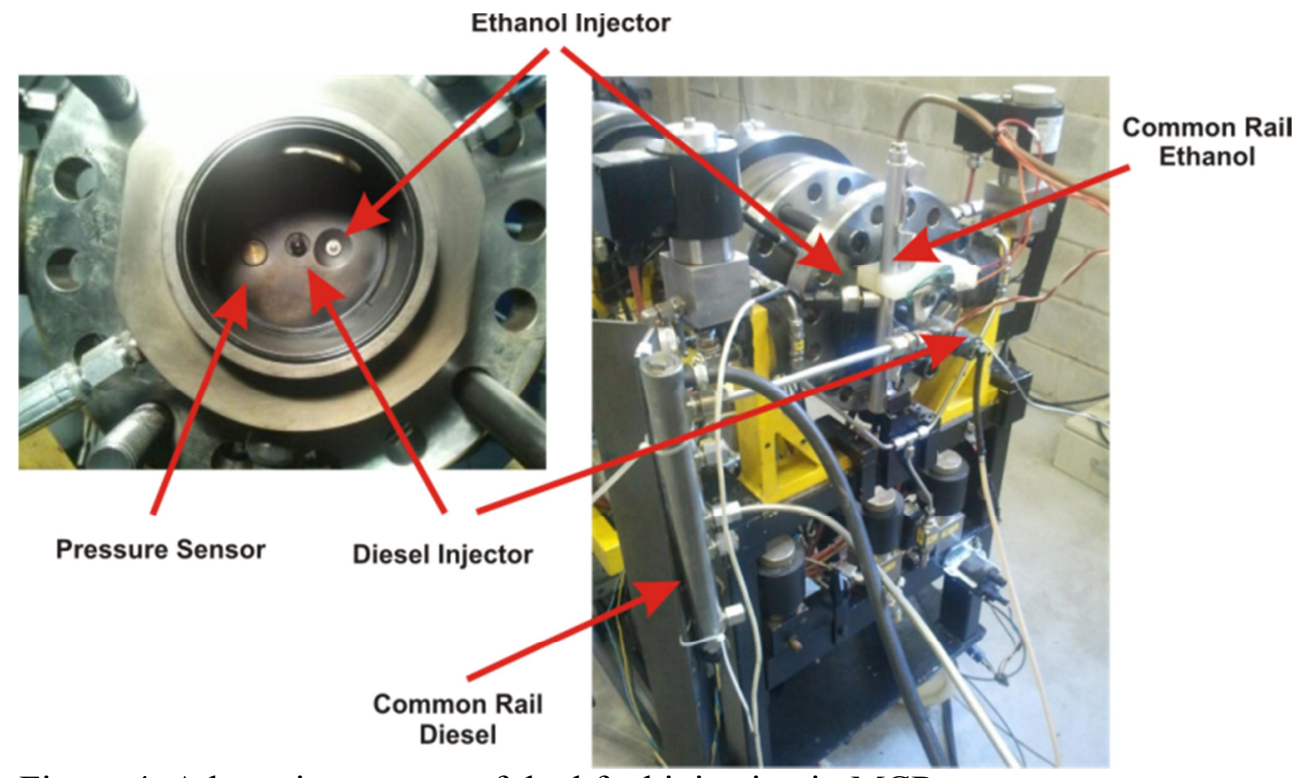

Figure 4. Adaptation system of dual fuel injection in MCR.

\section{TEST METHODOLOGY}

The RCM was equipped with high pressure common-rail diesel injection system and ethanol common rail injection system. The air was introduced in the combustion chamber before to compression and the Hydrous Ethanol H100 and Diesel S10 fuels were injected. 
The injection time and pressure of the Diesel S10 and H100 were readjusted in order to provide the same amount of chemical energy injected in a diesel combustion process. The characteristics of the engine used as reference are shown in Table 2.

Table 2. Reference Diesel engine characteristics.

\begin{tabular}{|l|l|}
\hline Bore & $85 \mathrm{~mm}$ \\
\hline Race & $88 \mathrm{~mm}$ \\
\hline Connecting rod length & $145 \mathrm{~mm}$ \\
\hline Misalignment & $0,4 \mathrm{~mm}$ \\
\hline Displacement & $1997 \mathrm{~cm} 3$ \\
\hline Number of cylinders / Architecture & 4 cylinders in line \\
\hline Number of valves / cylinder & 4 valves \\
\hline Nominal compression ratio & 16 \\
\hline Maximum power & $120 \mathrm{~kW} \mathrm{CEE}(163 \mathrm{ch} \mathrm{CEE})$ \\
\hline Maximum torque & $340 \mathrm{Nm}$ \\
\hline Idle cold & $800 \mathrm{tr} / \mathrm{mn}( \pm 20 \mathrm{tr} / \mathrm{min})$ à $20^{\circ} \mathrm{C}$ \\
\hline Idle hot & $750 \mathrm{tr} / \mathrm{mn}( \pm 10 \mathrm{tr} / \mathrm{min})$ à $80^{\circ} \mathrm{C}$ \\
\hline Plan maximum torque & $2000 \mathrm{tr} / \mathrm{mn}$ \\
\hline Maximum power speed & $3750 \mathrm{tr} / \mathrm{mn}$ \\
\hline Torque value to the Max & $301 \mathrm{Nm}$ \\
\hline Max rpm power (power flow) & $5000 \mathrm{tr} / \mathrm{mn}$ \\
\hline
\end{tabular}

The lower heating value (LHV) for the Diesel S10 is approximately $44.5 \mathrm{MJ} / \mathrm{kg}$ [17] and for the Hydrous Ethanol $\mathrm{H} 100$ is $24.9 \mathrm{MJ} / \mathrm{kg}$ [18]. Electrical heaters were adapted in both the upper part of the cylinder liner and in the piston head in order to achieve the proper thermal conditions of the combustion chamber during the experiments. The operation conditions for the tests are showed in the Tables 8, 9, 10 and 11that are in the Appendix. On the tests made with ethanol H100, the percentage load used is equivalent to the percentage load of Diesel S10 substituted.

\section{RESULTS}

The tests were conducted using Diesel S10 and Ethanol H100. The tests performed with Diesel S10 at the original injection timing condition, start of injection and pressure in the common rail, served as a reference for the tests with H100. The corresponding results of the tests are presented for compression ratios of 16:1 and 20:1.

\subsection{Tests with Diesel S10}

The tests with Diesel S10 were made changing the compression ratio and quantity of fuel injected. For the tests with $\mathrm{CR}=16: 1$ the SOI was $209 \mathrm{~mm}$ and for the tests with $\mathrm{CR}=20: 1$ the SOI was $212.6 \mathrm{~mm}$. Figure 5 shows the pressure behavior in the tests made using Diesel S10 and CR $=16: 1$. The pressure peak for the test with $25 \%, 50 \%$ and $100 \%$ load occurs about $0.83 \mathrm{~ms}, 0.47 \mathrm{~ms}$ and $0.15 \mathrm{~ms}$ after TDC respectively. For the tests with $\mathrm{CR}=16: 1$ and $\mathrm{CR}=20: 1$, when changing $\mathrm{CR}$ at MCR final displacement of the piston changes, therefore, also changes the injection point to maintain the same SOI of the reference engine described in Table 2. 


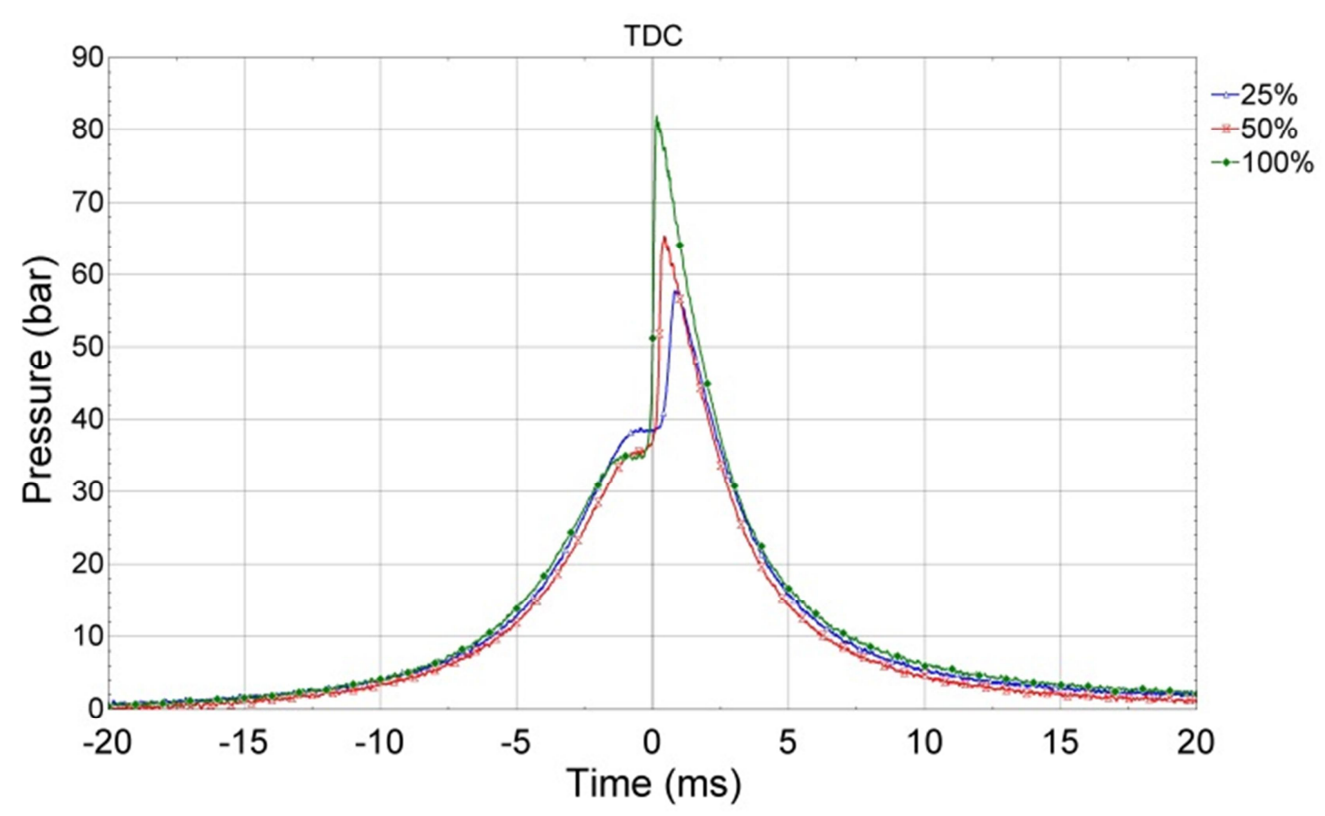

Figure 5. Cylinder pressure for the test with Diesel S10, CR $=16: 1, \mathrm{SOI}=209 \mathrm{~mm}$ (1.67 $\mathrm{ms}$ before TDC) and $1500 \mathrm{rpm}$.

It is important to note that the temperatures at which the RCM worked during the tests (average $55^{\circ} \mathrm{C}$, both the head and in the cylinder wall, product heating using electric heaters) will certainly influence the behavior of pressure inside the MCR. It is worth mentioning that these temperatures are low compared to those expected in engines, but here limited by the potential of low electrical resistance.

Table 3. ID using the indirect method for tests D-CR16.

\begin{tabular}{|c|l|l|l|l|l|}
\hline \multirow{2}{*}{ Test } & \multirow{2}{*}{ Load (\%) } & \multicolumn{4}{|c|}{ Ignition Delay } \\
\cline { 3 - 6 } & & \multicolumn{2}{|c|}{$\mathrm{dp}$} & \multicolumn{2}{c|}{$\mathrm{d}^{2} \mathrm{p}$} \\
\cline { 3 - 6 } & $\bar{X}(\mathrm{~ms})$ & $M D(\mathrm{~ms})$ & $\bar{X}(\mathrm{~ms})$ & $M D(\mathrm{~ms})$ \\
\hline D-CR16-1 & 25 & 1.20 & 0.10 & 0.86 & 0.11 \\
\hline D-CR16-2 & 45 & 1.21 & 0.25 & 0.83 & 0.33 \\
\hline D-CR16-3 & 50 & 1.21 & 0.15 & 0.61 & 0.09 \\
\hline D-CR16-4 & 60 & 1.16 & 0.02 & 0.57 & 0.03 \\
\hline D-CR16-5 & 75 & 1.13 & 0.03 & 0.48 & 0.11 \\
\hline D-CR16-6 & 100 & 1.07 & 0.07 & 0.81 & 0.12 \\
\hline
\end{tabular}




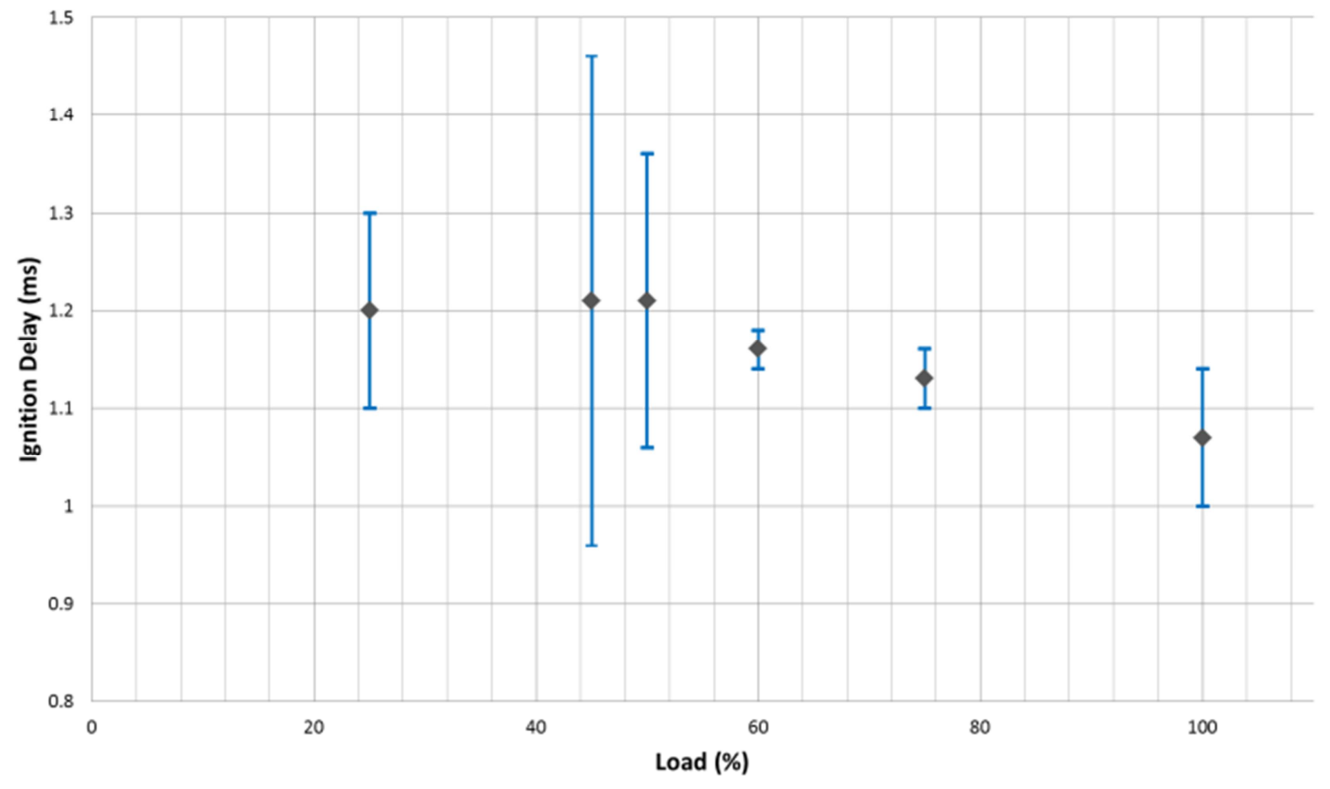

Figure 6. ID using the indirect method (dp) for tests D-CR16.

The Fig. 6 shows the behavior of the ignition delay determined by the method of the first derivative of the pressure. The maximum value of ID for the tests is $1.21 \mathrm{~ms}$ and the minimum value is $1.07 \mathrm{~ms}$.

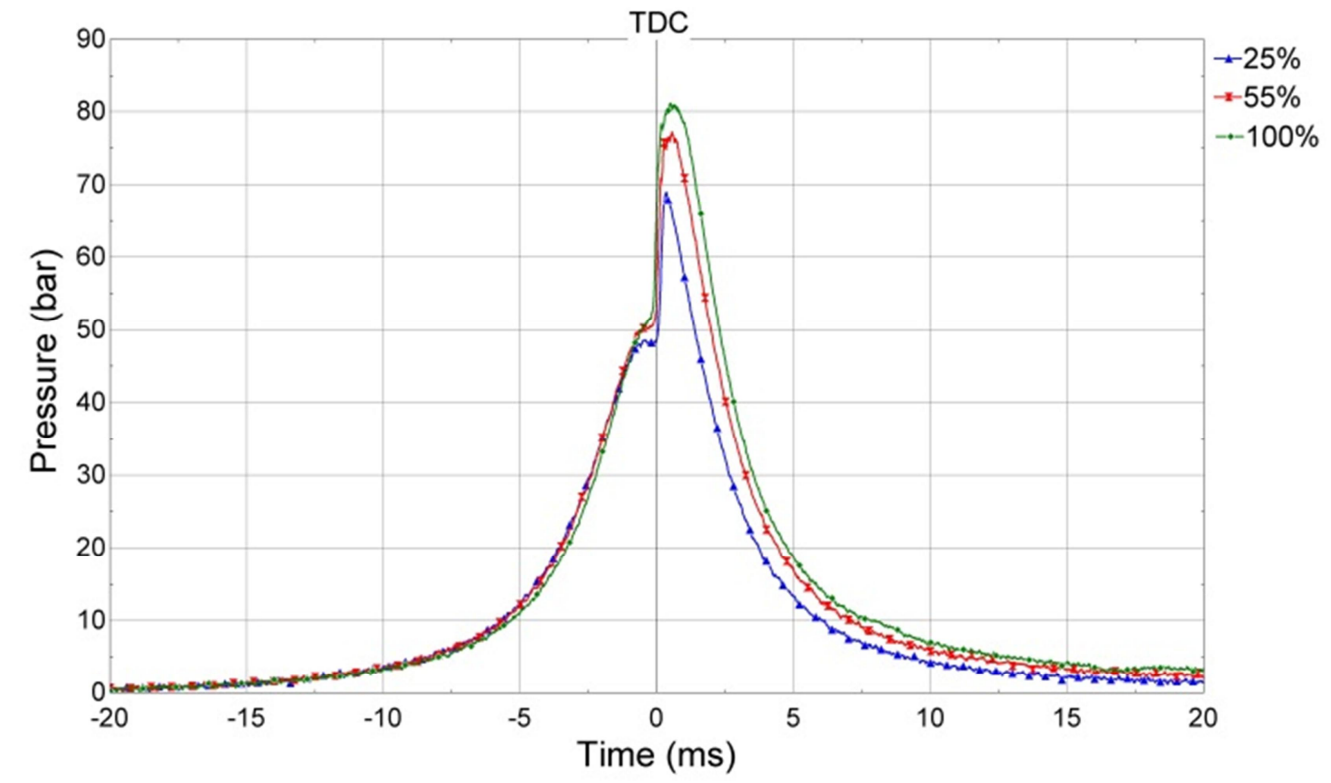

Figure 7. Cylinder pressure for the test with Diesel S10, CR $=20: 1, \mathrm{SOI}=212.6 \mathrm{~mm}$ (1.43 $\mathrm{ms}$ before TDC) and $1750 \mathrm{rpm}$.

Figure 7 shows the pressure behavior in the tests made using Diesel S10 and CR = 20:1. The pressure peak for the test with $25 \%, 55 \%$ and $100 \%$ load occurs about 0.34 $\mathrm{ms}, 0.55 \mathrm{~ms}$ and $0.49 \mathrm{~ms}$ after TDC respectively. 
Table 4. ID using the indirect method for tests D-CR20.

\begin{tabular}{|l|l|l|l|l|l|}
\hline \multirow{2}{*}{ Test } & \multirow{2}{*}{ Load (\%) } & \multicolumn{4}{|c|}{ Ignition Delay } \\
\cline { 3 - 6 } & & \multicolumn{2}{|c|}{$\mathrm{dp}$} & \multicolumn{2}{c|}{$\mathrm{d}^{2} \mathrm{p}$} \\
\cline { 3 - 6 } & $\bar{X}(\mathrm{~ms})$ & $M D(\mathrm{~ms})$ & $\bar{X}(\mathrm{~ms})$ & $M D(\mathrm{~ms})$ \\
\hline D-CR20-1 & 25 & 0.46 & 0.05 & 0.28 & 0.09 \\
\hline D-CR20-2 & 35 & 0.58 & 0.04 & 0.38 & 0.12 \\
\hline D-CR20-3 & 45 & 0.62 & 0.06 & 0.46 & 0.06 \\
\hline D-CR20-4 & 55 & 0.59 & 0.11 & 0.32 & 0.14 \\
\hline D-CR20-5 & 65 & 0.44 & 0.04 & 0.23 & 0.06 \\
\hline D-CR20-5 & 75 & 0.50 & 0.08 & 0.34 & 0.09 \\
\hline D-CR20-7 & 100 & 0.43 & 0.08 & 0.26 & 0.09 \\
\hline
\end{tabular}

Similarly as in Figure $5(\mathrm{CR}=16: 1)$, the maximum pressure reached $100 \%$ for a charge did not exceed 85 bar pressure. While the pressure levels were longer time compared to the same graph for $\mathrm{CR}=16$ : 1 , even if a greater charge injecting fuel and therefore providing more chemical energy.

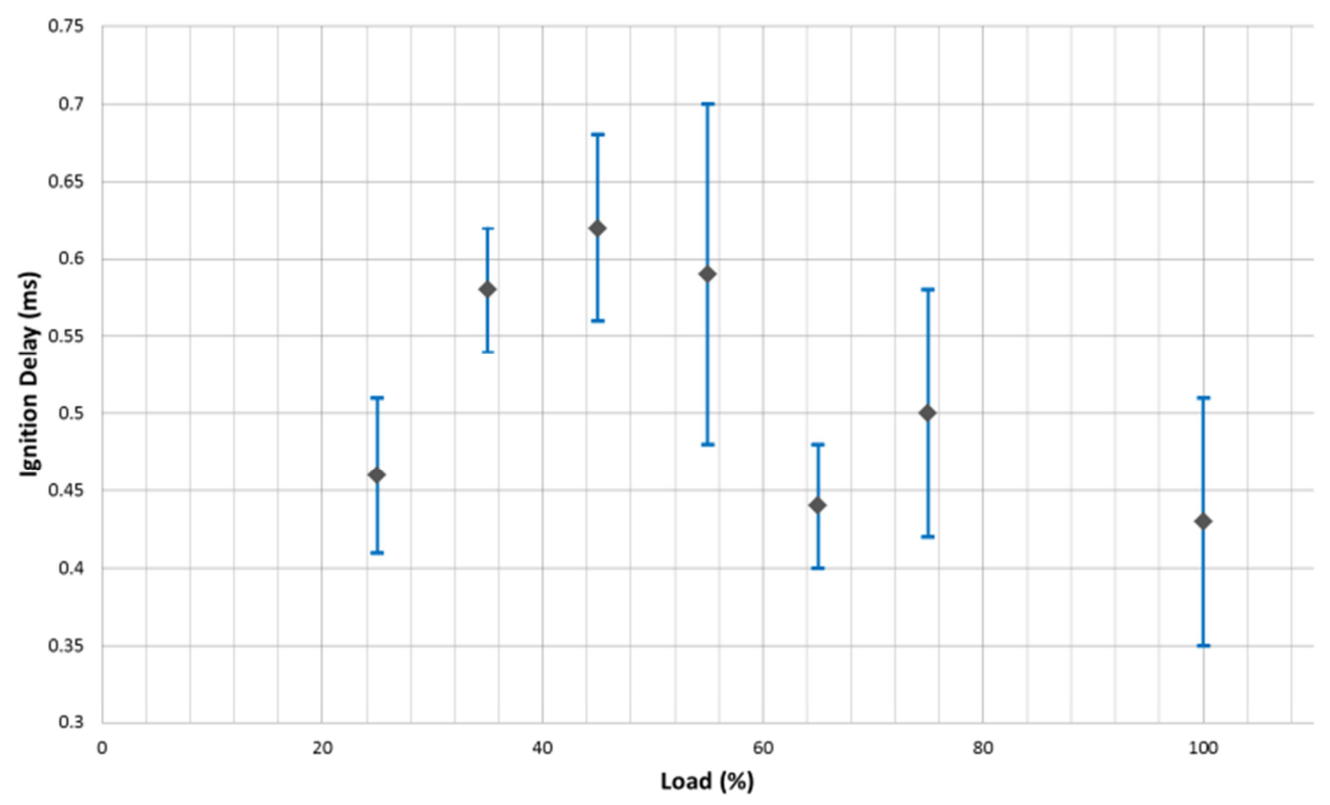

Figure 8. ID using the indirect method (dp) for tests D-CR20.

The Fig. 8 shows the behavior of the ignition delay determined by the method of the first derivative of the pressure. The maximum value of ID for the tests is $0.62 \mathrm{~ms}$ and the minimum value is $0.43 \mathrm{~ms}$.

By comparing the Tables 3 and 4, it is easy to notice the decrease of the ignition delay, due to the increasing of the compression ratio. When it is 16: 1, the ignition delay is $1.16 \mathrm{~ms}$, and when it is raised to $20: 1$, the ignition delay is reduced to approximately $0.5 \mathrm{~ms}$. 
5.2. Tests with Diesel S10 and Hydrated Ethanol H100, 75\% load and CR = 16:1 (DF1)

The tests with Diesel S10 and H100 were made changing the substitution rate and quantity of fuel injected. Figure 9 shows the pressure behavior in the tests (DF1).

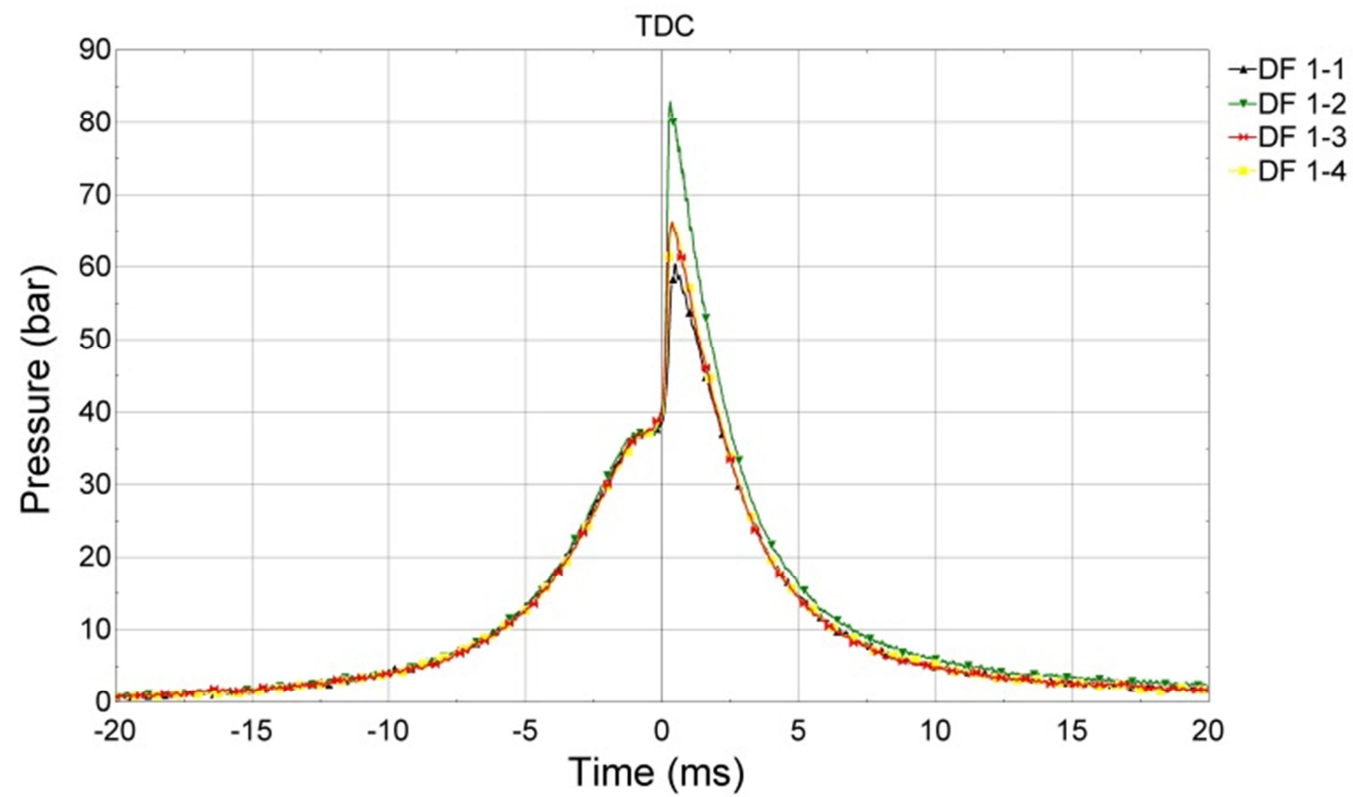

Figure 9. Cylinder pressure for the test with Diesel S10 and H100, CR $=16: 1,75 \%$ load and $1500 \mathrm{rpm}$.

The pressure peak for the test 1, 2, 3 and 4 occurs about $0.48 \mathrm{~ms}, 0.29 \mathrm{~ms}, 0.19 \mathrm{~ms}$ and $0.24 \mathrm{~ms}$ after TDC respectively.

DF1 test consisted of $25 \%$ of chemical energy supplied by ethanol and $45 \%$ of chemical energy provided by the diesel totaling a 75\% load. Picture 8 shows the behavior of the pressure curves of two strategies Dual Fuel (DF1-3 and DF1-4) compared with the curves for pressure loads only 25\% diesel fuel (DF1-2) and 60\% (DF1- 1) the maximum load. It is noticed that in Dual Fuel strategies pressure basically corresponds to the diesel oil charge DF1-1 (25\%) and is far from reaching the same pressure levels compared to diesel oil charge equivalent to the same injected chemical energy DF1-2 (60\%). Another point to note is the delay of the start of combustion in Dual Fuel strategy with pilot injection of ethanol.

Table 5. ID using the indirect method for tests DF1.

\begin{tabular}{|l|l|l|l|l|l|}
\hline \multirow{3}{*}{ Test } & \multirow{2}{*}{ Number } & \multicolumn{4}{|c|}{ Ignition Delay } \\
\cline { 3 - 6 } & & \multicolumn{2}{|c|}{$\mathrm{dp}$} & \multicolumn{2}{c|}{$\mathrm{d}^{2} \mathrm{p}$} \\
\cline { 3 - 6 } & & $\bar{X}(\mathrm{~ms})$ & $M D(\mathrm{~ms})$ & $\bar{X}(\mathrm{~ms})$ & $M D(\mathrm{~ms})$ \\
\hline \multirow{4}{*}{ DF1 } & 1 & 1,21 & 0,25 & 0,83 & 0,33 \\
\cline { 2 - 6 } & 2 & 1,13 & 0,03 & 0,48 & 0,11 \\
\cline { 2 - 6 } & 3 & 1,23 & 0,10 & 0,70 & 0,19 \\
\cline { 2 - 6 } & 4 & 1,16 & 0,19 & 0,67 & 0,09 \\
\hline
\end{tabular}


The Table 5 shows the behavior of ignition delay of combustion processes with energetic load of $75 \%$. Similarly to the previous case, the ethanol injection on the $\mathrm{BDC}$ decreases the ignition delay with respect to ethanol injection in the middle of the stroke.

In Table 5 it is observed the influence of ethanol on the ignition delay. In Dual Fuel process, the injection of ethanol on the BDC slows the onset of combustion in 0.03 ms. approximately with respect to the diesel combustion. The start of combustion is delayed approximately in $0.1 \mathrm{~ms}$. with respect to diesel combustion when the ethanol is injected in half the piston stroke.

\subsection{Tests with Diesel S10 and Hydrated Ethanol H100, 100\% load and CR = 20:1 (DF2)}

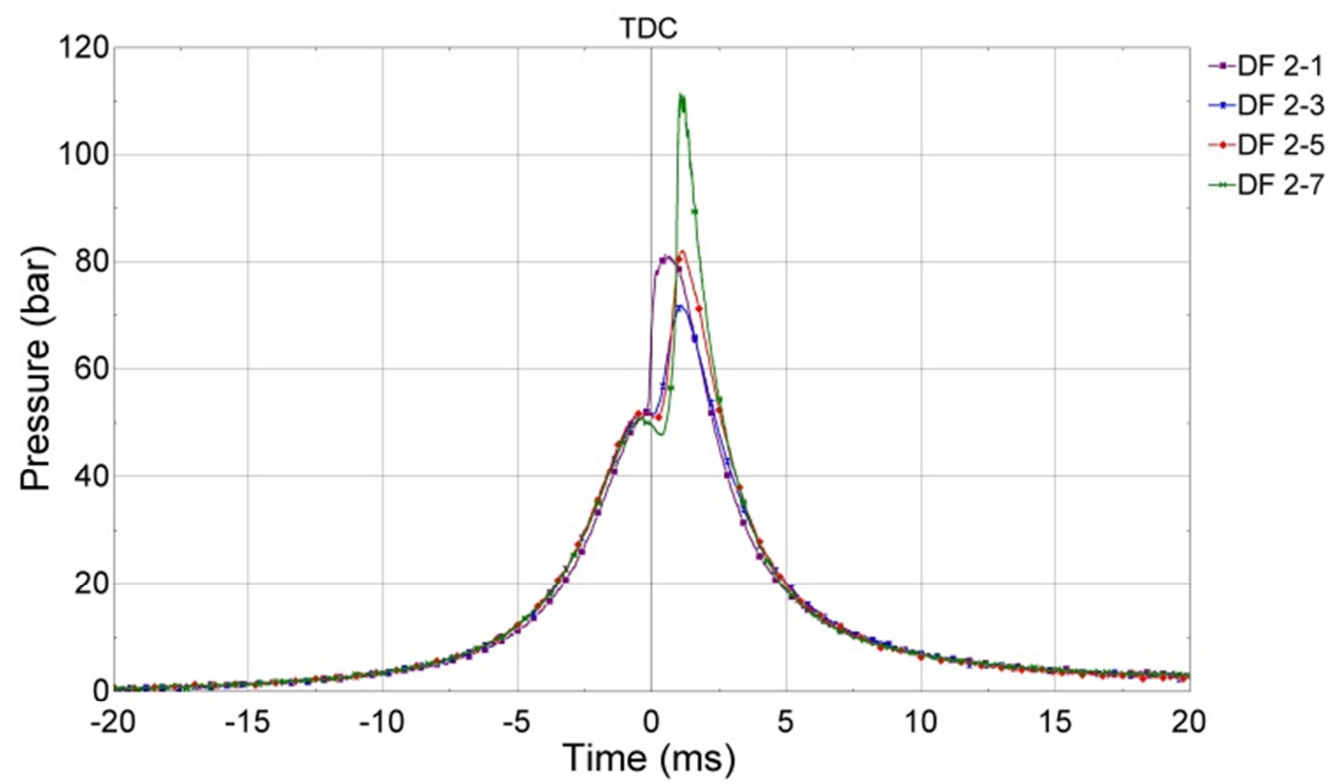

Figure 10. Cylinder pressure for the test with Diesel S10 and H100, CR $=20: 1,100 \%$ load and $1750 \mathrm{rpm}$.

The tests with Diesel S10 and H100 were made changing the substitution rate, compression ratio and quantity of fuel injected. In Figure 10 shows the some pressure behavior in the tests $1,3,5$ and 7 of DF3. The pressure peak for the test $1,3,5$ and 7 occurs about $0.49 \mathrm{~ms}, 1.1 \mathrm{~ms}, 1.12 \mathrm{~ms}$ and $1.11 \mathrm{~ms}$ after TDC respectively.

The curves variation corresponds to decreased chemical energy supplied by ethanol and increased chemical energy provided by the diesel oil. The premixed ethanol injection has a great influence on the delay time of combustion pressures. As the replacement ratio increased, higher pressures and delay times were perceived to $70 \%$ substitution ratios of $85 \%$ however the pressure increases anomalous happened for substitution ratio of $50 \%$. 
Table 6. ID using the indirect method for tests DF2.

\begin{tabular}{|l|l|l|l|l|l|}
\hline \multirow{3}{*}{ Test } & \multirow{2}{*}{ Number } & \multicolumn{4}{|c|}{ Ignition Delay } \\
\cline { 3 - 6 } & & \multicolumn{3}{|c|}{$\mathrm{dp}$} & \multicolumn{2}{c|}{$\mathrm{d}^{2} \mathrm{p}$} \\
\cline { 3 - 6 } & & $\bar{X}(\mathrm{~ms})$ & $M D(\mathrm{~ms})$ & $\bar{X}(\mathrm{~ms})$ & $M D(\mathrm{~ms})$ \\
\hline \multirow{5}{*}{ DF2 } & 1 & 0,43 & 0,08 & 0,26 & 0,09 \\
\cline { 2 - 6 } & 2 & 0,94 & 0,01 & 0,43 & 0,13 \\
\cline { 2 - 6 } & 3 & 0,89 & 0,07 & 0,48 & 0,05 \\
\cline { 2 - 6 } & 4 & 0,93 & 0,05 & 0,52 & 0,03 \\
\cline { 2 - 6 } & 5 & 1,19 & 0,10 & 0,54 & 0,05 \\
\cline { 2 - 6 } & 6 & 1,22 & 0,11 & 0,58 & 0,13 \\
\cline { 2 - 6 } & 7 & 1,29 & 0,19 & 0,81 & 0,21 \\
\hline
\end{tabular}

The Table 6 shows ignition delay behavior of combustion processes with energetic load of $100 \%$ for CR $=20: 1$. The H100 is injected into the BDC and the rate of substitution ranges from 50 to $90 \%$. The maximum value of delay time occurs when the rate of substitution is $50 \%$. It is observed in Table 6 the diesel replacement rate influence on the delay combustion, the dual fuel process has a greater delay with respect to the diesel combustion, but it is also observed that the higher is the rate replacing of diesel lower is the ignition delay.

5.4. Tests with single injection of Diesel S10 and two injections of Hydrated Ethanol $\mathrm{H} 100,100 \%$ load and $\mathrm{CR}=20: 1(\mathrm{DF} 3)$

The tests with Diesel S10 and H100 were made changing the substitution rate, SOI of H100 and quantity of fuel injected. Figure 11 shows the some pressure behavior in the tests $1,5,10$ and 15 of DF3. The pressure peak for the test 1, 5, 10 and 15 occurs about $0.49 \mathrm{~ms}, 0.82 \mathrm{~ms}, 1.1 \mathrm{~ms}$ and $0.52 \mathrm{~ms}$ after TDC respectively. Figure 11 shows the pressure curves for substitution ratios exceeding $70 \%$, where it is possible to realize higher values (below 10\%) of maximum pressures for all dual fuel strategies, compared to the combustion of pure diesel oil.

A larger ignition delay is noticed in the dual fuel strategy with two injections (ethanol - diesel) when compared to three injections (ethanol - diesel - ethanol), where this delay is less pronounced. This is justified by the greater presence of premixed ethanol in the first case. The simultaneous injection of ethanol with diesel oil, which until now did not appear to show greater benefits and may help to reduce the ignition delay, keeping the diesel fuel injection always at the same point. This indicates that it is possible to optimize the instant of injection 3, depending on the amounts of energy contained in each one.

The Table 7 shows the ignition delay behavior of combustion processes with energetic load of $100 \%$ for $\mathrm{CR}=20: 1$, with two ethanol injections. On the tests, $\mathrm{H} 100$ is injected into the BDC and on the same point that Diesel S10.Making two injections of ethanol, the ignition delay on the combustion process decreases with respect to the combustion process with a single injection of ethanol. In the combustion process with two ethanol injections, the ID increases, when higher percentage of ethanol is injected into the BDC. 


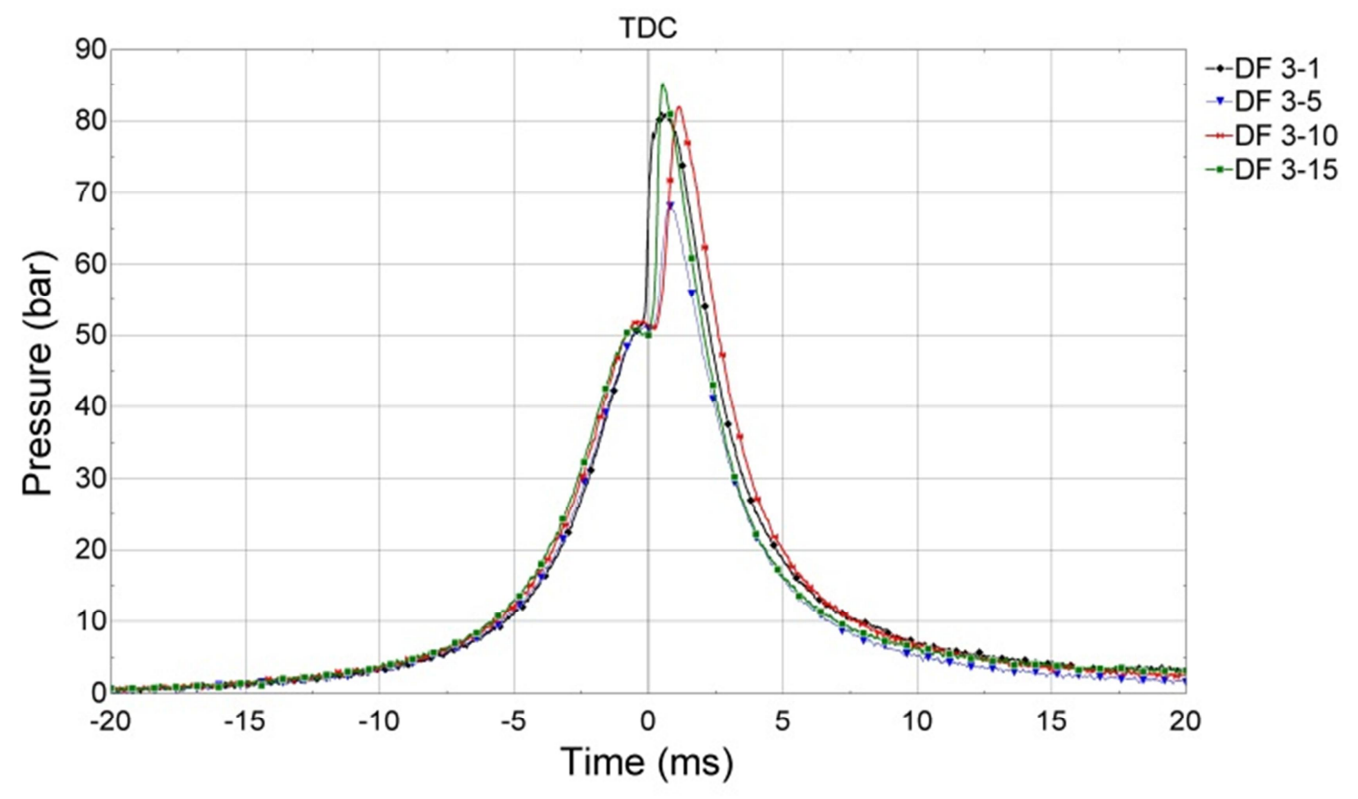

Figure 11. Cylinder pressure for the test with one injection of Diesel S10 and two injections of $\mathrm{H} 100, \mathrm{CR}=20: 1,100 \%$ load and $1750 \mathrm{rpm}$.

Table 7. ID using the indirect method for tests DF3.

\begin{tabular}{|l|l|l|l|l|l|}
\hline \multirow{3}{*}{ Test } & \multirow{3}{*}{ Number } & \multicolumn{4}{|c|}{ Ignition Delay } \\
\cline { 3 - 6 } & & \multicolumn{3}{|c}{$\mathrm{dp}$} & \multicolumn{2}{c|}{$\mathrm{d}^{2} \mathrm{p}$} \\
\cline { 2 - 6 } & $\bar{X}(\mathrm{~ms})$ & $M D(\mathrm{~ms})$ & $\bar{X}(\mathrm{~ms})$ & $M D(\mathrm{~ms})$ \\
\hline \multirow{6}{*}{} & 1 & 0.43 & 0.08 & 0.26 & 0.09 \\
\cline { 2 - 6 } & 2 & 0.94 & 0.01 & 0.43 & 0.13 \\
\cline { 2 - 6 } & 3 & 0.87 & 0.11 & 0.35 & 0.17 \\
\cline { 2 - 6 } & 4 & 0.89 & 0.07 & 0.48 & 0.05 \\
\cline { 2 - 6 } & 5 & 0.74 & 0.09 & 0.41 & 0.05 \\
\cline { 2 - 6 } & 6 & 0.67 & 0.05 & 0.32 & 0.05 \\
\cline { 2 - 6 } & 7 & 0.93 & 0.05 & 0.52 & 0.03 \\
\cline { 2 - 6 } & 8 & 0.82 & 0.25 & 0.37 & 0.05 \\
\cline { 2 - 6 } & 9 & 0.75 & 0.06 & 0.40 & 0.09 \\
\cline { 2 - 6 } & 10 & 1.19 & 0.10 & 0.54 & 0.05 \\
\cline { 2 - 6 } & 11 & 0.84 & 0.04 & 0.52 & 0.06 \\
\cline { 2 - 6 } & 12 & 0.83 & 0.06 & 0.50 & 0.07 \\
\cline { 2 - 6 } & 13 & 1.22 & 0.11 & 0.58 & 0.13 \\
\cline { 2 - 6 } & 14 & 0.84 & 0.07 & 0.52 & 0.07 \\
\cline { 2 - 6 } & 15 & 0.80 & 0.06 & 0.48 & 0.07 \\
\hline
\end{tabular}

\section{CONCLUSIONS}

The delay time decreases as the compression ratio increases during the compression ignition combustion process. It was observed that, if the diesel compression ratio changes from 16:1 to $20: 1$, the delay time of combustion decreases by about $55 \%$. For the dual fuel tests with a 
single injection of ethanol and $\mathrm{CR}=16: 1$, the delay time of combustion increases by about $10 \%$ when the energy load increases from $60 \%$ to $75 \%$. The ignition delay of the compression ignition process increases with the increase in ethanol mass fraction, compared with the combustion of Diesel oil.

The injection process with two injectors installed on the chamber combustion enables explores multiples possible modes of combustion. This allows injecting ethanol in the compression process before Diesel-SOI, during the Diesel injection and after Diesel-SOI.

For the substitution of diesel by ethanol on combustion processes for compression ignition, it is recommended the increase of the compression ratio and the addition of an additive to the ethanol. The additive must be a lubricity enhancer and corrosion inhibitor.

When the compression ratio increases, the combustion of ethanol H100 with Diesel S10 causes high pressure peaks. It can be observed a maximum peak of about 111 bar during the test DF3-7 (CR = 20:1). Therefore, the manufacturer must choose the option that has the best cost-benefit for the engine adaptation.

These results cannot be transferred directly to a motor, because the combustion process in the $\mathrm{RCM}$ is not a cyclical process, and has temperature limitations. For these reasons, do not truly represent the equivalent processes in engines. The results, however, indicate the paths to be followed in RCCI tests on engines. It is strongly suggested to work with higher compression ratios than the usual in CI engines. Early injections should be performed during the air intake process or, maximum, at the BDC. A second or even a third injection of ethanol can be done before and / or after the diesel SOI. When injected in large quantities the ethanol may impair the kinetics of combustion due to its high latent heat of vaporization.

\section{REFERENCES}

[1] Ometto, A., "Life Cycle Assessment of Hydrated Ethylic Alcohol Fuel by EDIP, Exergy and Emergy Methods," Ph.D thesis - Escola de Engenharia de São Carlos, Universidade de São Paulo, SP - Brazil, 2005, 209p.

[2] Goldenstein, M. and Azevedo, R., "Combustíveis Alternativos e Inovações no Setor Automotivo: Será o Fim da "Era do Petróleo"?,” BNDES Setorial , vol. 23, pag. 235 266, Rio de Janeiro - Brazil, 2006.

[3] Schaefer, A. and Hardenberg, H., "Ignition Improvers for Ethanol Fuels," SAE Technical Paper 810249, 1981, doi:10.4271/810249.

[4] Dickerson, M., "Brazil's ethanol effort helping lead to oil self-sufficiency," The Seattle Times, June 17, 2005.

[5] Sánchez, F., Braga, C., Braga, L., Braga, S. et al., "Ethanol-Powered Combustion Experimental Study in a Rapid Compression Machine," SAE Technical Paper 2013-360313, 2013, doi:10.4271/2013-36-0313.

[6] Yilmaz, N., Donaldson, A., and Johns, A., "Some Perspectives on Alcohol Utilization in a Compression Ignition Engine," SAE Technical Paper 2005-01-3135, 2005, doi:10.4271/2005-01-3135.

[7] Simonsen, H. and Chomiak, J., "Testing and Evaluation of Ignition Improvers for Ethanol in a DI Diesel Engine," SAE Technical Paper 952512, 1995, doi:10.4271/952512.

[8] Valdez, J., "Reactivity Controlled Compression Ignition of Diesel Fuel and Ethanol in Rapid Compression Machine," Ph.D thesis - Departamento de Engenharia Mecânica, Pontifical Catholic University of Rio de Janeiro, RJ - Brazil, 2005, 123p. 
[9] Kokjohn, S., Hanson, R., Splitter, D., Kaddatz, J. et al., "Fuel Reactivity Controlled Compression Ignition (RCCI) Combustion in Light- and Heavy-Duty Engines," SAE Int. J. Engines 4(1):360-374, 2011, doi:10.4271/2011-01-0357.

[10] Splitter, D., Reitz, R., and Hanson, R., "High Efficiency, Low Emissions RCCI Combustion by Use of a Fuel Additive," SAE Int. J. Fuels Lubr. 3(2):742-756, 2010, doi:10.4271/2010-01-2167.

[11] Curran, S., Hanson, R., Barone, T., Storey, J. et al., "Performance of Advanced Combustion Modes with Alternative Fuels: Reactivity Controlled Compression Ignition Case Study," Energy \& Transportation Science Division Oak Ridge National Laboratory, CBES Forum, January 19, 2012.

[12] Jayaraman, S. "Performance optimization of a Diesel Engine for Dual -Fuel Combustion," M.Sc. thesis - The Graduate School College of Engineering, The Pennsylvania State University, PA - USA, 2012, 136p.

[13] Heywood, J., "Internal Combustion Engine Fundamentals," Mc Graw-Hill Book Company, 1st Edition, (1988).

[14] Zou H.,Wang, L., Liu, S., Li, Y., "Ignition Delay of Dual Fuel Engine Operating with Methanol Ignited by Pilot Diesel," Front. Energy 2(3): 285-290, 2008, doi:10.1007/s11708-008-0060z.

[15] Reddy, P., Krishna, D., Mallan, K. and Ganesan, V., "Evaluation of Combustion Parameters in Direct Injection Diesel Engines - An Easy and Reliable Method," SAE Technical Paper 930605, (1993), doi:10.4271/930605.

[16] Shahabuddin, M., et al., "Ignition delay, combustion and emission characteristics of diesel engine fueled with biodiesel," Renewable and Sustainable Energy Reviews, vol. 21, pag. $623-632,2013$.

[17] Da Silva E. and Tôrres R. "Thermophysical Properties Of Diesel/Biodiesel Blends," 22nd International Congress of Mechanical Engineering (COBEM 2013), São Paulo - Brasil, pag. $6577-6584,2013$.

[18] Villela, A. and Machado, G., "Multifuel Engine Performance, Emissions and Combustion Using Anhydrous and Hydrous Ethanol," SAE Technical Paper 2012-36-0475, 2012, doi:10.4271/2012-36-0475.

\section{ACKNOWLEDGMENTS}

We would like to thank the engineer team of Vehicle Engineering Laboratory (VEL - PUCRio) 


\section{APPENDIX}

In the following Tables show the conditions of all tests, where is important to point out that the SOI used are: in the BDC, in the middle of the compression stroke ( $90^{\circ}$ before TDC) and $15^{\circ}$ before TDC.

Table 8. Input operations conditions for the test of Diesel S10 (D-CR16 and D-CR20) in the $\mathrm{RCM}$

\begin{tabular}{|l|l|}
\hline Compression ratio $(-)$ & $16: 1 / 20: 1$ \\
\hline Engine speed (rpm) & $1500 / 1750$ \\
\hline Maximum piston displacement $(\mathrm{mm})$ & 217 \\
\hline Driving pressure (bar) & $21.8 / 23.3$ \\
\hline Cyl. wall/piston head temperatures $\left({ }^{\circ} \mathrm{C}\right)$ & 55 \\
\hline Air combustion pressure (mbar) & 1100 \\
\hline Fuel & Diesel S10 \\
\hline LHV $(\mathrm{MJ} / \mathrm{kg})$ & 45 \\
\hline SOI $(\mathrm{mm})$ & $209 / 212.6$ \\
\hline Injection pressure of Diesel S10 $($ bar) & 1070 \\
\hline Load for CR $=16: 1(\%)$ & $100,75,60,50,45$ and 25 \\
\hline Load for CR $=20: 1(\%)$ & $100,75,65,55,45,35$ and 25 \\
\hline Injection time $(\mathrm{ms})$ for CR $=16: 1$ & $0.917,0.716,0.596,0.516,0.476$ and 0.315 \\
\hline Injection time $(\mathrm{ms})$ for CR $=20: 1$ & $1.318,1.017,0.897,0.776,0.656,0.536$ and 0.416 \\
\hline
\end{tabular}

Table 9. Input operations conditions for test dual fuel (DF1) with $75 \%$ of charge and CR $=$ $16: 1$ in the RCM.

\begin{tabular}{|l|l|}
\hline Compression ratio (-) & $16: 1$ \\
\hline Engine speed (rpm) & 1500 \\
\hline Maximum piston displacement (mm) & 217 \\
\hline Driving pressure (bar) & 21.8 \\
\hline Cyl. wall/piston head temperatures $\left({ }^{\circ} \mathrm{C}\right)$ & 55 \\
\hline Air combustion pressure (mbar) & 1100 \\
\hline Fuel & Diesel S10 / Ethanol H100 \\
\hline LHV (MJ/kg) & $45 / 24.9$ \\
\hline Load (\%) and SOI (mm) for test 1 & $45 / 0$ and $209 / 0$ \\
\hline Load (\%) and SOI (mm) for test 2 & $75 / 0$ and $209 / 0$ \\
\hline Load (\%) and SOI (mm) for test 3 & $45 / 30$ and $209 / 108.7$ \\
\hline Load (\%) and SOI (mm) for test 4 & $45 / 30$ and $209 / 0$ \\
\hline Injection pressure of fuel (bar) & $1070 / 100$ \\
\hline Injection time for test 1 (ms) & $0.476 / 0$ \\
\hline Injection time for test 2 (ms) & $0.716 / 0$ \\
\hline Injection time for test 3 (ms) & $0.476 / 3.087$ \\
\hline Injection time for test 4 (ms) & $0.476 / 3.087$ \\
\hline
\end{tabular}


Table 10. Input operations conditions for test dual fuel (DF2) with $100 \%$ of charge and CR $=$ $20: 1$ in the RCM.

\begin{tabular}{|c|c|}
\hline Compression ratio (-) & $20: 1$ \\
\hline Engine speed (rpm) & 1750 \\
\hline Maximum piston displacement $(\mathrm{mm})$ & 217 \\
\hline Driving pressure (bar) & 23.3 \\
\hline Cyl. wall/piston head temperatures $\left({ }^{\circ} \mathrm{C}\right)$ & 55 \\
\hline Air combustion pressure (mbar) & 1100 \\
\hline Fuel & Diesel S10 / Ethanol H100 \\
\hline LHV $(\mathrm{MJ} / \mathrm{kg})$ & $45 / 24.9$ \\
\hline $\mathrm{SOI}(\mathrm{mm})$ & $212.6 / 0$ \\
\hline Injection pressure of fuel (bar) & $1070 / 100$ \\
\hline Load $(\%)$ and injection time $(\mathrm{ms})$ for test 1 & $100 / 0$ and $1.318 / 0$ \\
\hline Load $(\%)$ and injection time $(\mathrm{ms})$ for test 2 & $10 / 90$ and $0.235 / 11.909$ \\
\hline Load $(\%)$ and injection time $(\mathrm{ms})$ for test 3 & $15 / 85$ and $0.295 / 11.279$ \\
\hline Load $(\%)$ and injection time $(\mathrm{ms})$ for test 4 & $20 / 80$ and $0.355 / 10.649$ \\
\hline Load $(\%)$ and injection time $(\mathrm{ms})$ for test 5 & $25 / 75$ and $0.416 / 10.019$ \\
\hline Load $(\%)$ and injection time $(\mathrm{ms})$ for test 6 & $30 / 70$ and $0.476 / 9.389$ \\
\hline Load $(\%)$ and injection time $(\mathrm{ms})$ for test 7 & $50 / 50$ and $0.716 / 6.868$ \\
\hline
\end{tabular}


Table 11. Input operations conditions for test dual fuel (DF3) with $100 \%$ of charge, three injections and $\mathrm{CR}=20: 1$ in the RCM.

\begin{tabular}{|c|c|}
\hline Compression ratio (-) & $20: 1$ \\
\hline Engine speed (rpm) & 1750 \\
\hline Maximum piston displacement (mm) & 217 \\
\hline Driving pressure (bar) & 23.3 \\
\hline Cyl. wall/piston head temperatures $\left({ }^{\circ} \mathrm{C}\right)$ & 55 \\
\hline Air combustion pressure (mbar) & 1100 \\
\hline Fuel & Diesel S10 / Ethanol H100 \\
\hline LHV (MJ/kg) & $45 / 24.9$ \\
\hline Injection mode & Ethanol H100 / Ethanol H100 / Diesel \\
\hline $\mathrm{SOI}(\mathrm{mm})$ & $0 / 212.6 / 212.6$ \\
\hline Injection pressure of fuel (bar) & $1070 / 100$ \\
\hline Load $(\%)$ and injection time $(\mathrm{ms})$ for test 1 & $0 / 0 / 100$ and $0 / 0 / 1.318$ \\
\hline Load $(\%)$ and injection time $(\mathrm{ms})$ for test 2 & $90 / 0 / 10$ and $11.909 / 0 / 0.235$ \\
\hline Load $(\%)$ and injection time $(\mathrm{ms})$ for test 3 & $55 / 35 / 10$ and $7.498 / 4.978 / 0.235$ \\
\hline Load $(\%)$ and injection time $(\mathrm{ms})$ for test 4 & $85 / 0 / 15$ and $11.279 / 0 / 0.295$ \\
\hline Load $(\%)$ and injection time $(\mathrm{ms})$ for test 5 & $55 / 30 / 15$ and $7.498 / 4.348 / 0.295$ \\
\hline Load $(\%)$ and injection time $(\mathrm{ms})$ for test 6 & $50 / 35 / 15$ and $6.868 / 4.978 / 0.536$ \\
\hline Load $(\%)$ and injection time $(\mathrm{ms})$ for test 7 & $80 / 0 / 20$ and $10.649 / 0 / 0.355$ \\
\hline Load $(\%)$ and injection time $(\mathrm{ms})$ for test 8 & $55 / 25 / 20$ and $7.498 / 3.718 / 0.355$ \\
\hline Load $(\%)$ and injection time $(\mathrm{ms})$ for test 9 & $50 / 30 / 20$ and $6.868 / 4.348 / 0.355$ \\
\hline Load $(\%)$ and injection time $(\mathrm{ms})$ for test 10 & $75 / 0 / 25$ and $10.019 / 0 / 0.416$ \\
\hline Load $(\%)$ and injection time $(\mathrm{ms})$ for test 11 & $50 / 25 / 25$ and $6.868 / 3.718 / 0.416$ \\
\hline Load $(\%)$ and injection time $(\mathrm{ms})$ for test 12 & $45 / 30 / 25$ and $6.238 / 4.348 / 0.416$ \\
\hline Load $(\%)$ and injection time $(\mathrm{ms})$ for test 13 & $70 / 0 / 30$ and $9.389 / 0 / 0.476$ \\
\hline Load $(\%)$ and injection time $(\mathrm{ms})$ for test 14 & $45 / 25 / 30$ and $6.238 / 3.718 / 0.476$ \\
\hline Load $(\%)$ and injection time $(\mathrm{ms})$ for test 15 & $40 / 30 / 30$ and $5.608 / 4.348 / 0.476$ \\
\hline
\end{tabular}

